\title{
Nhe'é para os Guarani (Nhandeva e Mbya)
}

\author{
SANDRA BENITES
}

MUSEU NACIONAL/UNIVERSIDADE FEDERAL DO RIO DE JANEIRO (UFRJ), RIO DE JANEIRO/RJ, BRASIL HTTPS://ORCID.ORG/0000-0003-4906-7794

Existem vários sentidos para as palavras nheeé e aywu em cada grupo Guarani. Geralmente, estas duas palavras são entendidas como espirito, ser, vida, palavras, falas, som que vem do py'a. Py'a traduzimos literalmente como estômago, mas esta expressão faz referência àquilo que fica no peito, que nós Guarani chamamos nhèe rapyta, a base fundamental de nhẽe, aywu e sentimento.

Para esclarecer melhor, darei exemplos dos significados de aywu e nhêe para os Mbya e os Nhandewa, os quais pude compreender melhor por ter vivido na aldeia Guarani Mbya no Espírito Santo, onde fui professora para crianças durante 7 anos. Atualmente, a comunidade Guarani do Espírito Santo se reconhece como Guarani Nhandewa. Na minha experiência como professora passei a usar as duas falas que aprendi, Mbya e Nhandewa. E eu mesma sou Nhandewa.

De acordo com o uso feito pelos Guarani Mbya da aldeia do Espírito Santo, aywu é a palavra que é utilizada no dia a dia, na fala comum, como, por exemplo, nas frases:

$$
\begin{aligned}
& \text { xe aywu porã - 'falei bonito' } \\
& \text { aywu reko rei - 'palavra à toa'. }
\end{aligned}
$$

A 'palavra à toa' não é vista positivamente, dá uma ideia de que é palavra jogada fora. É diferente de aywu xe ('desejo de falar'), que seria característico de uma pessoa que não sabe guardar segredo. Já a palavra nhěe apresenta outro tipo de complexidade. Nhèe é a fala de momentos específicos, como aqueles da casa de reza durante a fala religiosa, quando se trata de ser espirito. É também a fala utilizada para explicar a importância da origem do nome e de seu significado.

Essas duas palavras - aywu e nhêe - significam, no fundo, a mesma coisa, embora existam diferenças de significado nas variedades Mbya e Nhandewa. Para os Nhandewa da aldeia Porto Lindo (MS), da qual eu faço parte, aywu significa palavra sagrada e é o inverso da palavra nheế - que seria usada na fala comum do dia a dia entre nós. Um exemplo: 
nheê rei - 'palavra à toa'

nheễ se- 'desejo de fala' ( a pessoa que não sabe guardar segredo).

Ainda, nheẽ significa palavra sagrada quando se refere a um ser espirito. Os Nhandewa se referem a uma pessoa frágil como nheée kangy, e a uma pessoa forte como nheẽ mbarete. Essas palavras, portanto, têm mais ou menos o mesmo sentido para os Mbya e para os Nhandewa.

Segundo xe djaryi (minha avó), nheée é o que vem do amba (morada celeste) e quando uma pessoa morre, o nheê volta para o amba de onde veio. Deste modo, o nheế da pessoa que morreu pode voltar. Por exemplo, eu acredito que o nhe'é do meu sobrinho que faleceu voltou sobre meu filho caçula e voltou para mim.

Para nós, Nhandewa, aywu significa palavra sagrada que não é falada no dia a dia. É palavra sagrada usada no lugar onde é realizado o ritual, principalmente por pessoas como xamõi e djaryi. No entanto, quando se trata de um espírito ou ser pessoa - que entendemos como sagrados - falamos nhe ê e não usamos aywu. Raramente eu ouvia "aywu da pessoa" ou "aywu do fulano", sendo mais comum usar nhèe quando se fala de alguém. Geralmente, quando se realizam batismos, os mais velhos Guarani Nhandewa da aldeia Porto Lindo falam aywu, mas na hora de dar nomes para as crianças sempre falam nheêe. Mas também, como falei acima, para os Guarani Nhandewa da aldeia Porto Lindo (MS), a palavra nheẽé é a fala cotidiana.

Desse modo, eu pude perceber que a palavra nheée é entendida por todos os Guarani como sagrada quando se trata de um ser espirito e um sentimento (py'a). Existem nhe’é porã, nhe’é wai, nhèe kangy, nheê mbaraete, nheế katu, nheê gatu e assim por diante. Nhêéporã é 'palavra boa, bonita, linda'; é muito usada para dar conselho, para ser dirigida à pessoa que está emocionalmente abalada ou com raiva. Nhêe wai é 'palavra feia, ruim, agressiva' e é usada pela pessoa que geralmente não está bem. Nheế mbaraete é aquela das pessoas fortes, seguras e corajosas. Para os Nhandewa, pessoas que falam muito possuem nheê gatu. Já pessoas sensíveis, que sabem falar com tom de voz calmo, possuem nheee katu - fala essa que fortalece a pessoa que está escutando, passa segurança àqueles que estão com nheee fragilizado.

Cada nheéé é um processo que possui vários ritos de passagem, sendo direcionado a cada etapa em que se encontra cada Guarani. É um caminho (tape) para a construção de cada passo do indivíduo no grupo, lembrando-o sempre do coletivo. É importante destacar de cada indivíduo o estado em que ele se encontra emocionalmente, por isso esses aywu ou nhẽe porã - fala boa, ou boa fala - dependem do coletivo, do espaço dos elementos que formam o ser guarani. O ser guarani é construído por um conjunto de fatores. Para aproximar as expressões em Guarani e suas traduções em português, eu diria que, para nós Guarani, linguagem e o conceito de nheêe porã indicam a construção de um ser nhẻe mbaraete, que significa uma pessoa alegre, tolerante, paciente, que sabe escutar com sentimento. Essa pessoa é considerada uma pessoa saudável, alegre, forte, que tem facilidade de superar qualquer desafio. É uma pessoa arandu (sábia). Nhêe mbaraete também está relacionado com ritos, cantos, mitos e práticas do nhandereko, nosso modo de ser.

Para seguir as regras Guarani, é necessário compreender bem as palavras, seus significados e, principalmente, seus poderes de sentido. Entendo que é a partir de um processo, da prática do dia a dia 
e da forma de interpretar a vivência em grupo e entre grupos que cada indivíduo Guarani vai adquirindo a bo a fala em cada etapa da vida. Porém, é preciso que cada indivíduo tenha a possibilidade de construir o ser guarani no contexto no qual está inserido. Falar nem sempre é falado: é apenas vivido, sentido, experimentado. Isto é, falar muitas vezes não é visível e nem traduzido por palavras; é expressão do coletivo para o indivíduo.

Falas são palavras que vem do $p y^{\prime} a$, portanto cada palavra falada tem seu efeito, que são as reações às expressões. Sendo expressões, muitas falas não têm como ser traduzidas, sendo apenas, talvez, possível que sejam demonstradas. Quem pode captá-las são aqueles que estão aptos a compreender. Assim, percebo que há uma dificuldade de interpretação, senão de compreensão, do mundo dessas línguas faladas. No meu entendimento, não são apenas os não falantes que têm dificuldades de compreender a complexidade da língua guarani por inteiro. Os próprios guarani falantes têm algumas dificuldades de perceber o que seria uma boa fala. Quando se trata de tradução e bilinguismo, preciso entender também o mundo da língua do outro para traduzir em português, por exemplo. Para evidenciar a suavidade da língua guarani para o português, preciso transmitir aspectos do guarani através de metáforas.

Eu pude perceber que muitos Guarani que vivem mais tradicionalmente têm facilidade de ensinar suavemente os seus conselhos por meio da fala, porque conseguem emocionar, encantar e convencer sem usar palavras fortes, ou seja, sem fazer uso de tom de voz alterado. Para nós, Guarani, todos os espaços são importantes para nhomongueta (dialogar): nas reuniões da comunidade, na casa de reza, na família, entre irun (amigos, amigas), durantes as atividades de plantar, na construção da casa, etc.

Existem palavras que podem ser ditas para brincar, outras palavras para serem ditas durante ritos, existem os cantos, e também falas para zombar do outro. E existem as falas das mães, que são também os cantos de ninar que cada mãe vai criando para cantar. Mas é preciso ter certos cuidados. Certas falas são comparadas a bichinhos pelos quais podemos nos encantar ou que podem nos encantar. Cada um desses bichos têm suas narrativas, que contam processos de encantamento. Segundo os mais velhos, aqueles que se sentem mais espertinhos caem nas palavras desses seres sarcásticos.

Palavras engraçadas, geralmente, são usadas pelos Guarani para enganar a raiva e as decepções, sobretudo quando geram uma crise de risos na pessoa guarani. Esses risos muitas vezes não são relacionados apenas a coisas engraçadas, são também uma forma de descontaminar o ambiente, afastando a tristeza ou aquilo que pode causar algo de ruim aos outros. Para não se deixar levar por tristeza e transformar o nhêe wai (ruim, mal, feio), para driblar a tristeza ou a raiva, estes se transformam no oposto, o riso excessivo, que também pode ser sinal de raiva ou tristeza. Um bom falante Guarani sabe superar, por isso é importante treinar seu ouvido e coração " $p y^{\prime} a$ ". Assim, fica mais fácil controlar seu ser, essa pessoa sendo geralmente mais saudável. Mas para preparar a pessoa, como também para saber falar e ouvir, é necessário treino. Trata-se de ouvir com o ouvido e colocar no coração ( $\left.p y^{\prime} a\right)$, não apenas ouvir por um ouvido e mandar para o outro ouvido. Ouvir e sentir no py'a, colocar no py'a re (guardar no coração). Para isso, é preciso tempo, atenção e cuidado minucioso para cada Guarani. Por isso, a grande maioria dos Guarani não faz perguntas sobre algo que não sabe, mas sim sobre algo que já sabe. Perguntar o que não sabe é uma forma de provocação, é um sinal de que a pessoa não está de acordo com aquilo que está sendo dito ou proposto. 
A maioria dos Guarani não gosta de pessoas que falam muito, que emitem muitas palavras sem necessidade. Estas pessoas não são bem vistas: segundos os anciãos(ãs), são pessoas que têm dificuldade de concentração. Uma palavra wai, nheee wai, deixa o outro machucado, triste, pode até mesmo ferir profundamente e abalar a vida de uma pessoa. Por esta razão, as palavras para nós Guarani devem ser construídas e emitidas como nhẻe porã, ou seja, como aywu porã. Eu ouvia muito minha avó dizer que uma mãe que está esperando filho não pode falar que não vai querer o filho quando nascer, em nenhum momento. Neste caso, pode ocorrer, depois do nascimento e quando a mãe menos espera, de a criança querer voltar para o amba (morada celeste). Os mais velhos sempre orientam as mães a não falar palavras à toa por impulso, na hora da raiva, se referindo aos filhos. Houve um caso de uma mãe que estava esperando um filho e, em um momento de raiva, falou que não iria querer o bebê quando nascesse. Essa criança nasceu e quando a mãe já estava esquecendo aquilo que tinha falado, quando menos esperava, essa criança ficou doente e faleceu. Foi muito difícil para a mãe superar a dor da perda do filho. Em outros casos, quando acontecer de a criança não voltar - pois isso significa não apenas literalmente morrer -, ela pode se tornar uma pessoa problemática que dará muito trabalho aos pais.

A fala boa (nhễe ou aywu porã), para os Guarani, não é apenas a escrita, é a vivida; nem sempre palavras e fala com emoção passam para a escrita. O problema surge do fato de que nem todas as palavras e jeitos de se expressar podem ser escritos. Há uma limitação, sendo necessário arandu (conhecimento) para abordar assuntos específicos de forma compreensível. Partes do arandu dos Guarani são impossíveis de traduzir, porque existem conhecimentos que só podem ser compreendidos quando vividos.

Por isso, para os Guarani, o que está no papel não é tão importante. O que causa um efeito imediato são as práticas do dia a dia. Os diferentes conhecimentos dos juruá estão no papel, ficam parados e não acompanham o movimento, omyı̆ wa'e e guata, o caminhar. Nós acreditamos mais na nossa história, porque ela nos ensina a construir teko porã, o 'bem-viver'. Minha avó dizia que não se pode acreditar muito no papel, pois o papel é cego, a escrita não tem sentimentos, não anda, não respira, é história morta. É preciso ter cuidado com isso, apesar de que hoje em dia faz parte da nossa vida também. Nós Guarani temos a ideia de que sempre precisamos andar para frente (guata tenonde), nessa caminhada que não sabemos como vai ser. Para se preparar e enfrentar o caminho com sabedoria é importante guardar (nhongatu) nossa sabedoria para quando precisarmos.

\section{Sandra Benites é doutoranda em linguistica na UFRJ}




\section{NHE' É PARA OS GUARANI (NHANDEVA E MBYA)}

Resumo: Os termos nhe'é e aywu apresentam semelhanças e contrastes nos usos que deles fazem os Guarani Nhandeva os Guarani Mbya. Dentre os muitos sentidos evocados por ambos, destacam-se espírito, ser, vida, palavras, falas, som. Se para os Guarani Mbya, a fala comum é associada ao termo aywu, entre os Nhandeva este termo é utilizado para se referir às palavras sagradas. Nhe'é, por sua vez, é o termo utilizado pelos Nhandeva na fala comum, enquanto para os Guarani Mbyá é utilizado como palavra sagrada. Sem enrijecer distinções, este texto mostra que, entre os Nhandeva, nhe ée é também utilizado como palavra sagrada quando se refere a um ser espírito ou a um sentimento. Neste texto, busco apontar para a importância da boa fala para a construção da pessoa guarani, um caminho (tape) para o bem viver, teko porã.

Palavras-chave: Palavra; fala; Guarani; Nhe'ée; Aywu.

\section{NHE ' $\tilde{E}$ FOR THE GUARANI (NHANDEVA E MBYA)}

Abstract: The terms nhe'é and aywu show similarities and contrasts in the uses that the Guarani Nhandeva and the Guarani Mbya make of them. Among the many meanings evoked by both, spirit, being, life, words, speech, sound stand out. If for Guarani Mbya, common speech is associated with the term aywu, among Nhandeva this term is used to refer to sacred words. Nhe' $\tilde{e}$, in turn, is the term used by the Nhandeva in common speech, while for the Guarani Mbyá it is used as sacred word. Without hardening distinctions, this text shows that, among the Nhandeva, nhe' $\tilde{e}$ is also used as sacred word when referring to a spirit being or a feeling. In this text, I try to point out the importance of good speech for the construction of the Guarani person, a path (tape) for good living, teko porã.

Keywords: Word; speech; Guarani; Nhe'ée; Aywu.

RECEBIDO: $30 / 11 / 2019$

APROVADO: $30 / 03 / 2020$ 
42 Campos v21 N.1 p. 37-41 jan.jun. 2020 